\title{
Mudança Institucional em Regimes de Direitos Humanos: o Sistema Interamericano e os Estados "em cima do muro"1
}

\author{
Institutional change in Human Rights Regimes: \\ the Inter-American System And States 'on the fence'
}

DOI: $10.21530 /$ ci.v12n2.2017

Isabela Gerbelli Garbin Ramanzini²

\section{Resumo}

O objetivo do artigo consiste em analisar o desenvolvimento institucional do Sistema Interamericano de Direitos Humanos (SIDH) sob o prisma da relação entre a Comissão Interamericana de Direitos Humanos (CIDH) e os Estados não jurisdicionados. A seleção desse grupo de Estados - que se manteve "em cima do muro" ao longo do processo de transformação do sistema regional em um sistema protetivo - representa um ponto de partida pouco explorado. Como esses Estados encontram-se comprometidos em menor grau com as obrigações regionais de direitos humanos, é comum receberem a pecha de obstáculos à universalização do SIDH. As raras referências aos Estados não jurisdicionados nos estudos sobre o SIDH se restringem a qualificá-los como impedimentos à expansão e ao adensamento institucional do sistema regional. Os achados da pesquisa permitem rivalizar com essa ideia, sugerindo que, embora comprometidos em menor grau, a presença e a participação dos Estados não jurisdicionados no SIDH são parcelas explicativas não apenas do design institucional e funcionamento peculiar do SIDH, mas também da própria continuidade do sistema regional de direitos humanos, por representarem a construção de um fator de estabilidade institucional dentro de um panorama persistente de questionamentos da própria ideia de proteção interamericana dos direitos humanos na região.

Palavras-chave: instituições internacionais; regimes internacionais; direitos humanos; sistema interamericano de direitos humanos

1 Esse artigo resulta de projeto de pesquisa financiado pelo CNPq

2 Fellow no Carr Center for Human Rights Policy, Harvard Kennedy School. E-mail: isabela_garbin@hks.harvard.edu Artigo submetido em 06/02/2017 e aprovado em 17/04/2017. 


\begin{abstract}
The aim of this article is to analyze the institutional development of the Inter-American Human Rights System (IAHRS) under the prism of the relationship between the Inter-American Commission on Human Rights (IACHR) and the non-jurisdictional states. The selection of this group of states - which remained 'on the fence' throughout the process of transforming the regional system into a protective system - represents a little explored starting point. As these States are less committed to regional human rights, they are often referred as obstacles to IAHRS's universalization. The rare references to the non-jurisdictional states in the IAHRS's studies are restricted to qualifying them as impediments to the expansion and to the institutional strengthening of the regional system. The findings of this research allow us to rival this idea, suggesting that, although less committed, the presence and the participation of the non-jurisdictional states in the IAHRS are explanatory parcels not only of the institutional design and functioning of the IAHRS, but also of the continuity of the regional human rights system because they represent the construction of a factor of institutional stability within a persistent panorama of questions of the very idea of inter-american protection of human rights in the region.
\end{abstract}

Keywords: International institutions; international regimes; human rights; inter-american human rights system

\title{
Introdução
}

O Sistema Interamericano de Direitos Humanos (SIDH) conta, atualmente, com 68 anos de existência normativa e 57 anos de funcionamento institucional. Não obstante a duração relativamente extensa desse arranjo regional, o SIDH está longe de se afirmar consensual; pelo contrário, seu histórico institucional vê-se marcado por questionamentos, desde a origem e cada vez de forma mais estridente, por parte dos governos e dos movimentos transnacionais. Num contexto prevalecente de incertezas quanto à política regional no campo dos direitos humanos, uma das indagações mais comuns, dado o binômio resistência (institucional)/hesitação (estatal) no SIDH, refere-se às mudanças e continuidades ao longo de sua trajetória institucional: em quais aspectos seria possível apontar mudanças e continuidades no SIDH? As mudanças institucionais promovidas no SIDH foram substantivas ou apenas graduais? Quais elementos tornaram possíveis mudanças e continuidades institucionais no SIDH? 
Diversas perspectivas lidam com a análise do desenvolvimento institucional do SIDH. Alguns estudos (ALVES, 1997; TRINDADE, 2002) dedicam-se ao exame, geralmente legalista, da produção de normas no SIDH, notadamente, dos tratados interamericanos de direitos humanos. Como resultado, traçam um percurso de sucessões normativas ao longo da existência do sistema regional ${ }^{3}$. Outros trabalhos voltam-se à evolução jurisprudencial (PASCUALUCCI, 2003; PIOVESAN, 20011 RAMOS, 2001), destacando tanto o gradual incremento de matérias substantivas (direitos civis e políticos, direitos econômicos e sociais, proteção às minorias: mulheres, crianças, indígenas e LGBTI), como ganhos em termos procedimentais (excepcionalidade ao esgotamento dos recursos domésticos, controle de convencionalidade, por exemplo) nos órgãos interamericanos. Há trabalhos que lidam com o progresso na participação de atores não estatais no SIDH, avaliando tanto as estratégias desses atores (CAVALLARO; BREWER, 2008a, 2008b), quanto a receptividade do sistema às suas demandas por participação (JIMÉNEZ et al., 2015), de modo que a evolução do SIDH se demonstra a partir dos ganhos na transparência institucional e na participação dos atores não estatais nos mais diversos procedimentos institucionais (opiniões consultivas, processos de reformas institucionais, amicus curiae, entre outros). Alguns trabalhos analisam o desenvolvimento do SIDH a partir do acúmulo de trabalho nos órgãos interamericanos e da capacidade institucional em lidar com os casos da região (BASCH et al., 2010). Também figuram narrativas de experiências profissionais no SIDH (FARER, 1997; BUERGHENTHAL, 2005; MEDINA, 1990), que mesclam percepções pessoais de ex-burocratas às análises sobre as instituições interamericanas. Por fim, há pesquisas que se dedicam à evolução institucional dos órgãos interamericanos, primando pela avaliação dos ganhos de autonomia e competência dos órgãos interamericanos (THEDE; BRISSON, 2011; GOLDMAN, 2009), perspectiva na qual esse artigo se enquadra. Contudo, diferentemente de outros trabalhos, não pretendemos oferecer uma análise estática, a partir da qual se ateste, dentre um regulamento interamericano e outro, a mera adição de competências institucionais, ou a simples descrição de incrementos orçamentários e de infraestrutura institucional. Preocupa-nos, sobretudo, os elementos políticos que orientam as mudanças e continuidades no SIDH.

3 Por exemplo: Carta da OEA e Declaração Americana de Direitos e Deveres do Homem (ambas de 1948), Convenção Americana de Direitos Humanos (1969), Protocolo de San Salvador (1988), Convenções Interamericanas da década de 1990, e assim por diante. 
Há de se destacar, todavia, que os múltiplos processos de transformação institucional no SIDH envolvem uma intensa variabilidade de contextos (local, nacional, regional, global) e de interações estratégicas entre atores de natureza diversa. Essa complexidade causal impõe desafios teóricos e empíricos às tentativas de explorar o tema, frequentemente, também porque os processos de mudança, não raro, são carregados de efeitos não intencionais, de múltiplas causas, de diversos mecanismos causais, quase sempre produzidos por causação conjunta (REZENDE, 2013). Este trabalho propõe enfrentar a questão da mudança e continuidade institucional no SIDH por meio do estudo da relação entre a Comissão Interamericana de Direitos Humanos (CIDH) e os Estados não jurisdicionados. A seleção, em especial, desse grupo de Estados - que se manteve "em cima do muro" ao longo do processo de transformação do sistema regional em um sistema protetivo - representa um ponto de partida pouco explorado.

Como esses Estados encontram-se formalmente comprometidos em menor grau com as obrigações regionais de direitos humanos, é comum receberem, por parte da literatura e do ativismo transnacional, a pecha exclusiva de obstáculos à universalização do SIDH. Portanto, as raras referências aos Estados não jurisdicionados nos estudos sobre o SIDH se restringem a qualificá-los como impedimentos à expansão e ao adensamento institucional do sistema regional. Os achados desta pesquisa permitem rivalizar com essa ideia, sugerindo que, embora "menos" comprometidos, a presença e a participação dos Estados não jurisdicionados no SIDH são parcelas explicativas não apenas do design institucional e funcionamento peculiar do SIDH, mas também da própria continuidade do sistema regional de direitos humanos, ao representarem a construção de um fator de estabilidade institucional dentro de um panorama regional persistente de questionamentos da própria ideia de proteção interamericana dos direitos humanos na região.

$\mathrm{O}$ artigo encontra-se estruturado da seguinte forma. Na primeira seção, apresentamos uma leitura sobre o SIDH enquanto espaço de disputas políticas. Esse ponto contribui para a reflexão sobre a influência dos elementos de poder (não apenas estatal) na explicação das mudanças e continuidades no SIDH. A seção seguinte identifica dois momentos críticos na trajetória institucional da $\mathrm{CIDH}$, como medida comparativa para analisar as trajetórias de mudança e continuidade institucional no órgão interamericano. A última seção examina a relação entre a CIDH e os Estados não jurisdicionados, de acordo com os momentos críticos estabelecidos na seção anterior. Dados - admissibilidade, 
mérito, medidas cautelares, observações in loco, nacionalidade dos comissionados, proporção regional entre comissionados e juízes, entre outros - permitem qualificar a participação dos Estados não jurisdicionados no SIDH entre os períodos, conformando, portanto, indicativos para avaliar quando e como a posição política "em cima do muro" desse grupo de Estados contribui para as mudanças e continuidades no SIDH.

\section{SIDH: espaço de disputas políticas}

Assim como outros sistemas internacionais de direitos humanos, o SIDH, por lidar com questões de alta carga valorativa e com a busca pela responsabilização de Estados por violação ao direito internacional, costuma ser associado, inicialmente, à imagem de uma estrutura neutra, operada por um corpo burocrático, voltada para a promoção de ideais universalmente aceitas. Nessa lógica, a instituição internacional operaria, praticamente, de forma automática e quase que inercial. Outra forma, menos asséptica, de enxergar o SIDH, e por consequência os próprios direitos humanos, seria assumi-los como luta pela afirmação de determinados valores e identidades e enquanto espaço-ação permeado e definido em razão dos conflitos de poder entre atores de natureza diversa. O SIDH representaria, portanto, o resultado dos compromissos políticos, suportados por coalizões de poder. A partir desse raciocínio, as mudanças e continuidades - perspectivas fundamentalmente conectadas - dependeriam de ações coletivas e/ou da coordenação entre os atores para se concretizarem, uma vez que as reformas institucionais corresponderiam a propostas de mudança na distribuição de poder entre agentes, algo geralmente sensível (MAHONEY; THELEN, 2010).

Nessa lógica, a OEA e o SIDH situam-se como o compromisso resultante das disputas político-ideológicas contrastantes a respeito dos moldes e limites da cooperação regional, em particular, no campo dos direitos humanos. O estabelecimento de relações pan-americanas (sob a liderança dos Estados Unidos), ao final do século XIX, representou uma transição decisiva do conceito de bolivarianismo (que favorecia arranjos em torno de uma comunidade política latino-americana) para uma ideia de cooperação interamericana, isto é, do Norte direcionada ao Sul (DYKMANN, 2004). O enquadramento das relações interamericanas no formato de relações dos Estados Unidos para a América 
Latina produziu, ao menos, dois efeitos duradouros no SIDH: (i) uma profunda desconfiança em relação às intenções dos Estados Unidos no arranjo institucional (a qual, inúmeras vezes, ao longo da história do SIDH, é retomada como argumento estratégico pelos governos acusados por violações de direitos humanos) e (ii) o paradoxo da coexistência, normativa e prática, dos princípios da não intervenção e da proteção aos direitos humanos (embate principiológico constantemente desafiado pela CIDH e Corte IDH).

Há de se ter em mente, portanto, que a OEA e o SIDH, desde suas origens e cada vez mais acentuadamente, representam espaços marcados por conflitos de poder entre os diversos atores neles envolvidos, de modo que a configuração de forças regionais, o comportamento estratégico de determinados Estados (mais resistentes ou cooperativos) e dos próprios órgãos interamericanos (não apenas tomados monoliticamente, mas também em razão das individualidades dos comissionados, juízes e demais burocratas) são variáveis explicativas importantes para entender as mudanças e continuidades no SIDH.

Enquanto espaço marcado pelo conflito de poder, as análises sobre a trajetória institucional do SIDH geralmente privilegiaram a influência dos fatores estruturais (choques externos advindos da Guerra Fria, crises econômicas e financeiras na América Latina), das dinâmicas regionais (guerras civis, conflitos políticos, golpes militares, novos movimentos de concertação regional) e os Estados relativamente mais poderosos na região (notadamente os Estados Unidos, Canadá, Brasil, México, Chile e Argentina) para explicar as mudanças e continuidades do SIDH. Por certo, os estudos com foco na presença hegemônica dos Estados Unidos (DONNELLY, 1986, 2003; FORSYTHE, 1991; FARER, 1988; SHOULTZ, 1981), na ausência significativa do Canadá (STEVENSON, 1994; FRANÇA, 2013), na importância estratégica do envolvimento de potências menores como Brasil (AMORIM, 2009) e na excepcionalidade dos desdobramentos de experiências políticas traumáticas, como os regimes ditatoriais do Chile e Argentina (SIKKINK; WALLING, 2010; LUTZ; SIKKINK, 2000; ENGSTROM, 2013), assumem relevância especial nesse tipo de análise. O que pretendemos demonstrar, nesse artigo, é que o foco em Estados menos poderosos (ainda que muitas vezes implicitamente alinhados aos interesses de Estados mais poderosos) pode contribuir para um entendimento mais amplo e matizado do SIDH. Não argumentamos que os Estados não jurisdicionados, no caso desse artigo, tenham precedência explicativa sobre as demais variáveis, mas também não desmerecemos por completo a seu envolvimento no SIDH, tampouco 
os resultados institucionais possibilitados pela sua presença e participação em momentos críticos desse sistema regional ${ }^{4}$.

Os aqui denominados Estados "em cima do muro" se diferenciam dos demais Estados engajados no SIDH em razão de sua objeção circunstancial 5 à jurisdição da Corte IDH. Compõem esse grupo ${ }^{6}$ : Antígua e Barbuda, Bahamas, Belize, Canadá, Cuba, Dominica, Estados Unidos, Guiana, Granada, Jamaica, São Cristóvão e Nevis, Santa Lucia e São Vicente e Granadinas. Há de se reconhecer que esse universo congrega Estados com mais disparidades do que semelhanças, diferenciando-se substantivamente em relação ao poderio econômico, nível de desenvolvimento, tamanho da população e território, tradições históricas, trajetórias políticas, posição geográfica (insular ou continental), entre outras medidas de comparação. Todavia, a combinação dos princípios da soberania e da igualdade formal dos Estados no plano internacional permite delimitar tal grupo em função das suas preferências normativas dentro do SIDH, ainda que haja variações substantivas no padrão de atuação particular de cada Estado nesse sistema regional.

Conformando pouco mais do que um terço (37\%) dos Estados membros do SIDH, os Estados não jurisdicionados não costumam ser considerados significativos para o entendimento do desenvolvimento institucional no SIDH, com exceção, obviamente, dos EUA? ${ }^{7}$. Como se encontram comprometidos em menor grau com os acordos regionais de direitos humanos, a presença e participação desse grupo são, geralmente, compreendidas nos termos do impasse que representam para transformação do SIDH em um sistema de alcance universal ${ }^{8}$. De forma contraintuitiva, argumenta-se que os Estados não jurisdicionados podem ser

4 Conforme resposta proferida a comentário recebido por Comissionado da Comissão Interamericana de Direitos Humanos, em versão anterior do artigo.

5 Esse elemento indica que tais Estados podem mudar, a qualquer momento, sua preferência no SIDH, bastando, para isso, a aceitação integral da CADH.

6 Uma ressalva se faz necessária nesse ponto. A menção ao termo "grupo" não faz referência a uma atuação necessariamente coletiva desses Estados no SIDH, mesmo porque não há indícios formais de que esses Estados ajam coletivamente por meio dos instrumentos/mecanismos interamericanos. Portanto, o uso da expressão "grupo", neste trabalho, refere-se exclusivamente ao agrupamento de Estados em função de preferências iguais quanto à participação formal no SIDH.

7 Os Estados Unidos assumem papel central no SIDH, mesmo formalmente comprometido em menor grau. Alguns elementos fáticos sustentam essa afirmação: sede da OEA e da CIDH em Washington, D.C., financiamento de $2 / 3$ das atividades do sistema regional, presença ininterrupta de um comissionado indicado pelos EUA na CIDH e a participação de juízes norte-americanos na Corte IDH (tribunal ao qual não se submete).

8 A questão da universalidade do SIDH diz respeito à aplicação de um único sistema de regras (padrão de funcionamento) para todos os Estados membros da OEA. Fundamenta-se, mas não se confunde, com a universalidade dos direitos humanos, característica particular das normas de direitos humanos que se refere à aplicação a todos os seres humanos, em qualquer época e em todas as culturas das normas de direitos humanos. 
elementos chave para a compreensão das mudanças e continuidades institucionais do SIDH, principalmente no que se refere à trajetória excepcional de permanência institucional da CIDH em um ambiente politicamente hostil. A análise da presença e participação dos Estados não jurisdicionados em cada um dos momentos críticos do SIDH, descritos nas seções seguintes, fornece subsídios para pensar quando e como esses Estados influenciaram mudanças e continuidades na CIDH, trazendo elementos à uma reflexão mais ampla e matizada sobre o desenvolvimento institucional do SIDH.

\section{Comissão Interamericana de Direitos Humanos: momentos críticos}

A CIDH foi o primeiro órgão a ser criado no âmbito do SIDH, em 1959, e, desde então, tem se mostrado resistente aos mais diversos desafios de continuidade institucional: é questionada por manter o SIDH atado a um design institucional supostamente ultrapassado e ineficiente (se comparado a outros sistemas regionais, como o Sistema Europeu de Direitos Humanos, por exemplo); é contestada pelo viés político impresso em suas ações; e é restringida em suas atuações pelas frequentes restrições orçamentárias impostas pelos governos e pela própria OEA. Mesmo diante de conjunturas, na prática, permanentemente desfavoráveis à sua continuidade institucional, é interessante notar que a CIDH não só se manteve como órgão interamericano, como ampliou consideravelmente seu status institucional na OEA e seus poderes ao longo do tempo. Ou seja, é preciso reconhecer que a CIDH continuou existindo no SIDH e, ao mesmo tempo, enfrentou mudanças graduais que a fortaleceram enquanto instituição, ainda que, em muitos momentos, o cenário esperado fosse o oposto. Nesta seção, pretendemos entender os elementos objetivos de mudança e continuidade na CIDH por meio da comparação analítica entre dois momentos críticos da história institucional do órgão. Definimos como momentos críticos da trajetória institucional da CIDH aqueles processos de mudança que envolveram diretamente a possibilidade de extinção do órgão interamericano por vias formais, isto é, por meio de alterações das normas constitutivas dos órgãos interamericanos ${ }^{9}$.

9 Por certo, é possível sinalizar outros momentos críticos da trajetória institucional do SIDH como, por exemplo, a repercussão da crise financeira da OEA e da crise da dívida na América Latina durante a década de 1980, que quase levaram a organização internacional ao colapso financeiro; a atual proclamada "crise financeira sem precedentes” do SIDH (2016), com demissões em massa dos funcionários do sistema regional e cancelamento de sessões e observações in loco. Todavia, essas crises se diferenciam dos momentos críticos indicados neste 
Considera-se que o primeiro momento crítico a colocar desafios à continuidade institucional da CIDH remete à transição do SIDH para um sistema protetivo, processo que se deu entre os anos de 1969 a 1979, com a adoção da Convenção Americana de Direitos Humanos (CADH) e a efetiva implementação da Corte IDH. Apesar de o SIDH ter sido fundado em bases normativas amplas que permitiram, tempos depois, o surgimento de um tribunal regional, no início do funcionamento do SIDH, eram baixas as expectativas institucionais e os interesses estatais em torno da existência de uma Corte de direitos humanos na região, fato que se depreende ante o decurso temporal entre a previsão legal (CADH, 1969) e a efetiva criação da Corte IDH (1979). A entrada em vigor da CADH marcou a transição para o design final do SIDH, momento em que seria vital para a continuidade do órgão precedente (CIDH) que as prerrogativas dos órgãos interamericanos (adiante CIDH e Corte IDH), na qualidade de características identitárias, estivessem minimamente definidas.

A CIDH foi concebida, originariamente, como órgão autônomo à OEA. Constituía um grupo de estudos voltado a duas atividades principais: (i) documentar violações de direitos humanos e indicar formas de melhorar as condições de direitos humanos nos Estados (âmbito quasi-judicial) e (ii) servir de instância consultiva da OEA em temas de direitos humanos (âmbito promocional). Um dos capítulos mais interessantes da história institucional do SIDH - e sobre o qual pouco se discorreu - foi justamente a elevação da CIDH a órgão principal da OEA, em 1967, a partir do Protocolo de Buenos Aires. As narrativas a respeito dessa transformação institucional geralmente atribuem tal ascensão ao reconhecimento da OEA em relação aos trabalhos realizados pela CIDH. Isso não deixa de ser verdade: à época, a CIDH já contava com boa reputação e com um importante trabalho junto à questão da crise política na República Dominicana, tendo sido, inclusive, indicada ao Nobel da Paz em 1967 (DYKMANN, 2004). Todavia, pouco se debateu a respeito das implicações políticas e institucionais relativa à ascensão da CIDH.

Enquanto a CIDH mantinha o status de entidade autônoma ${ }^{10}$, suas ações estavam atreladas ao Conselho Permanente da OEA, fórum de menor calibre da organização. Ademais, nessa condição subalterna, qualquer resolução passada perante o conselho seria suficiente para extinguir a CIDH. Nota-se, portanto, uma intenção dupla no movimento de alçar a CIDH a um novo status: ampliar e elevar

artigo por caracterizarem formas indiretas - mas não apolíticas - de extinguir ou deixar sem efeito os órgãos interamericanos. Agradeço a Oscar Parra, pela reflexão sobre esse ponto.

10 A concepção da CIDH como entidade autônoma serviria aos propósitos de manter a neutralidade política e autonomia geral dos trabalhos desempenhados pela instituição. 
o fórum decisivo sobre a CIDH e restringir a possibilidade de transformações substantivas no órgão, ambas no intuito de conferir maior solidez institucional à continuidade da CIDH. A principal razão apontada para essa reforma estrutural estaria na insatisfação, notadamente norte-americana, com a ineficiência da OEA em lidar com os problemas econômicos e sociais do hemisfério. Os Estados Unidos enxergavam a OEA como uma conexão onerosa, pouco efetiva, mas necessária com a América Latina; enquanto que a CIDH, a seus olhos, parecia-lhe um instrumento muito mais útil e efetivo (DYKMANN, 2004). Para a CIDH, a proposta também se mostrava altamente interessante, de modo que o status de órgão principal teria o potencial de conferir-lhe, ainda que limitadamente à época, maior autonomia e poder institucional. Quando a CIDH é elevada a órgão principal, passa a submeter-se à Assembleia Geral da OEA, fórum superior e mais "democrático", onde os Estados Unidos teriam supostamente mais influência"1. Nessa nova circunstância, qualquer proposta de modificação (ou extinção) da CIDH prescindiria de emenda à Carta da OEA, um processo, portanto, muito mais dificultoso. Essa jogada combinada de interesses norte-americanos e da própria $\mathrm{CIDH}$ pavimentou o caminho para assegurar a continuidade institucional da CIDH em um terreno normativo e institucional mais firme.

Ainda que com maior solidez normativo-institucional, a previsão de uma corte regional configura o primeiro momento crítico do SIDH, principalmente por colocar em xeque a exclusividade da CIDH em assuntos de direitos humanos na região. Ademais, por estar inicialmente prevista como pacto facultativo, pairava no ar um importante dilema de interpretação das regras do SIDH: para alguns, a $\mathrm{CADH}$, ao entrar em vigor, condicionaria as atividades de ambos os órgãos (CIDH e Corte IDH) à ratificação desse novo documento. Isto é, para que a CIDH continuasse existindo, haveria a necessidade de novo chancelamento estatal de seu mandato (FARER, 1997). Essa nova rodada de aceitação da CIDH poderia se mostrar bastante perigosa para a continuidade do órgão interamericano, principalmente porque, à época, a CIDH já havia começado a dar sinais de sua potencialidade em "incomodar” alguns governos da região.

Em resposta, a CIDH começou a delinear novas versões de seus estatuto e regulamento, condizentes com uma interpretação própria e autointeressada dos dispositivos da $\mathrm{CADH}$, segundo a qual entendeu que a única modificação

11 De acordo com Álvaro Tirado Mejía, ministro das Relações Exteriores da Colômbia: “A reforma do Protocolo de Buenos Aires foi o produto do desejo da América Latina de obter assistência econômica e cooperação dos Estados Unidos” (apud DYKMANN, 2004, p. 63). 
promovida pela entrada em vigor da Convenção Americana foi a adição de uma nova competência à CIDH, específica para dos Estados dela ratificadores (FARER, 1997). Na visão da CIDH, a CADH investiu-lhe um papel duplo: reteve seu status de órgão da OEA, com poderes de promover e proteger os direitos humanos nos Estados partes da CADH e, em adição, tornou-se órgão membro da CADH, com poderes sobre os Estados partes da CADH. Nessa competência adicional, a CIDH passou a atuar em conjunto com a Corte IDH no sistema interamericano de petições. A manutenção das competências anteriores à CADH não só foi um trunfo para garantir exercício sobre todos os Estados membros da OEA, como também para reter certas capacidades conferidas pelo mandato original, como a discricionariedade em iniciar relatórios gerais e conduzir observações in loco sem a permissão dos governos investigados. Como resultado desse processo, observa-se uma renovação formal das funções da CIDH, em que seus poderes também foram ampliados. Ao fim desse primeiro momento crítico, a CIDH passou a cumular outras atividades relevantes, como redigir relatórios anuais e estabelecer um incipiente sistema de recebimento de petições individuais.

Em que pesem os saldos positivos para a CIDH, uma das principais decorrências desse primeiro momento crítico consiste na estruturação do SIDH em função de um duplo padrão de funcionamento ${ }^{12}$. Nele se agregam elementos de hard e soft law $^{13}$ para tornar possível a participação de Estados comprometidos em maior e em menor grau com o sistema regional de direitos humanos. Portanto, o design final do SIDH simboliza, nesse momento, o consenso político possível para a continuidade do sistema regional, de modo que a universalidade - ou o padrão único e, no caso, mais rígido - é rebaixado de pré-requisito para participação no SIDH a mero objetivo institucional, prioritariamente a cargo da CIDH. A busca, ainda que incipiente, pela realização desse objetivo da universalização do SIDH é deflagrada pela CIDH apenas quando as relações entre os órgãos interamericanos

12 O SIDH conta com três níveis de aceitação estatal: (i) anuência apenas aos instrumentos normativos elementares do regime (Carta da OEA e Declaração Americana de Direitos e Deveres do Homem); (ii) anuência aos instrumentos normativos elementares em conjunto com a CADH, sem aceitação da jurisdição da Corte IDH; e (iii) anuência aos instrumentos normativos elementares em conjunto com a CADH, com aceitação da jurisdição da Corte IDH. Na prática institucional, esses três níveis de aceitação podem ser traduzidos no duplo padrão de atuação do SIDH: um, em que apenas a CIDH é órgão reconhecido pelos Estados; e outro em que ambos órgãos interamericanos têm reconhecimento estatal.

13 De acordo com Goldstein (2000), ao traçar um acordo internacional, os governos não enfrentam uma escolha binária entre normas rígidas e brandas. A legalização é um processo marcado por nuances, de modo que os Estados moldam os elementos normativos (obrigação, precisão e delegação) de acordo com suas preferências. Logo, o design do regime internacional tem importância para que os consensos sejam ajustáveis e não rompam a essência do acordo ao longo do tempo (HELFER, 2002). 
se tornam mais amistosas, o que ocorre a partir de 1981, quando a CIDH envia acidentalmente - o primeiro caso ao tribunal regional. Após uma série de reuniões conjuntas para a coordenação dos trabalhos no sistema interamericano de petições individuais, na segunda metade dos anos de 1990, a CIDH passa a incluir - de forma não sistemática e quase ocasional - em seus Relatórios Anuais uma lista de Estados pendentes quanto à adesão à CADH. A ausência de registros, nesses documentos, sobre as atividades relativas à universalização do SIDH, aliás, reforça a ideia de que tal objetivo não mereceu atenção devida da CIDH, pelo menos até o segundo momento crítico.

O segundo momento crítico a colocar desafios à continuidade institucional da $\mathrm{CIDH}$ se refere ao processo de reforma do SIDH, tendente a revisar o funcionamento desse órgão interamericano. Tal processo foi iniciado em junho de 2011, durante a XLI Assembleia Geral da OEA e formalmente finalizado em 201314, com a conclusão das recomendações definidas pelo Grupo de Trabalho Especial de Reflexão sobre o Funcionamento da CIDH para o Fortalecimento do SIDH. Esse momento configura-se crítico ${ }^{15}$ dada a centralidade que o embate entre os Estados jurisdicionados e não jurisdicionados ganha no processo de reforma institucional, ensejando questionamentos sobre o duplo padrão do SIDH, além de propostas radicais, como: mudança de sede física, cerceamento de poderes e, no limite, a dissolução formal da CIDH. A agenda de reformas ${ }^{16}$ caracterizou-se pela assimetria, estando mais focada em abordar as preocupações e interesses de alguns Estados do que de outros atores participantes do sistema (MUÑOZ; ZICCARDI, 2013). Como resultado, as mudanças implementadas por meio desse processo se restringiram ao âmbito do funcionamento do SIDH, tergiversando quanto às outras medidas importantes pendentes de revisão, como, por exemplo, o fomento ao cumprimento estatal e às contribuições financeiras ao regime regional.

14 O desfecho desse processo, apesar de formalmente conclusivo, não colocou fim ao debate sobre as reformas no SIDH. Pelo contrário, por voto dos 35 Estados membros da OEA, deixou-se em aberto a possibilidade da continuidade dos diálogos para reforma.

15 A própria CIDH reconhece a criticalidade do momento ao lançar o seguinte comunicado de imprensa: “CIDH adverte que se atravessa um momento crucial para o Sistema Interamericano de Direitos Humanos”, em que o Presidente da CIDH afirma: “O que está em jogo, que ninguém tenha dúvida, é o patrimônio que os Estados, a sociedade civil e os próprios órgãos interamericanos temos construído para que as atuais e futuras gerações de todo o hemisfério possam todo gozar de seus direitos humanos” [tradução nossa]. Comunicado de Imprensa n. 58/12, 06. Jun. 2012. Disponível em: < http://www.oas.org/es/cidh/prensa/comunicados/2012/058.asp > . Acesso em: 16 set. 2015.

16 Durante o processo, foram abordados oito temas: nomeação do Secretário Executivo da CIDH; desafios de médio e longo prazo da CIDH; medidas cautelares; assuntos de procedimento na tramitação de casos e petições individuais; soluções amistosas; critérios para construção do capítulo 4 do Relatório Anual da CIDH; promoção dos direitos humanos; e fortalecimento financeiro do SIDH. 
Apesar dos resultados pouco favorecedores ao efetivo fortalecimento institucional do SIDH, esse segundo momento crítico reforça a ideia do sistema regional enquanto campo de disputas políticas. Frente aos desafios de continuidade institucional, a CIDH agiu com protagonismo, nesse caso, participando de todas as reuniões do Grupo de Trabalho e registrando seu posicionamento em relação a cada uma das recomendações adotadas pelo Conselho Permanente da OEA. Paralelamente aos encontros dessa ocasião em especial, a CIDH levou a cabo uma série de audiências e fóruns de debate público em diversos Estados membros para envolver interessados e usuários do SIDH no debate sobre a relevância da atuação do órgão interamericano. Um dos movimentos importantes da CIDH, nesse segundo momento crítico, foi o lançamento do Plano Estratégico: 2011-2015, documento que sinaliza uma busca pelo aperfeiçoamento do seu modus operandi, no intuito de: reforçar a importância da atuação histórica da CIDH (inclusive com apelos à reprodução de cartas e depoimentos pessoais de vítimas e seus familiares); mostrar capacidade e, sobretudo, imparcialidade de ação do órgão; e justificar os resultados de suas atividades aos financiadores das atividades. O Plano Estratégico exprime uma versão "executiva” da CIDH, traçando planos, programas de ação e estratégias milimetricamente delineadas dentro de calendários programáticos, fluxos de ação e da metodologia de Administração Baseada em Resultados. Diferentemente da abordagem dos Relatórios Anuais da CIDH, o registro confere evidência ao obstáculo da aceitação universal do SIDH, traçando estratégias para superá-lo ${ }^{17}$. Todavia, quando tomado em conjunto com os demais objetivos, se verifica que a questão da universalização do SIDH encontra-se diluída nas outras atividades do órgão, que não constituem os pilares ${ }^{18}$ de atuação da CIDH. Assim, apesar da CIDH dar visibilidade à questão durante o segundo

17 "No período de 2011 a 2015, a Comissão vai aproveitar todos os seus mecanismos para trabalhar pela aceitação universal dos instrumentos interamericanos de direitos humanos. Durante suas visitas in loco, por exemplo, irá desenvolver e buscar uma agenda de diálogo político com os seguimentos executivo e legislativo dos governos que, por uma questão de rotina, incluem uma revisão do status de ratificação dos instrumentos regionais e convidá-los à ratificação quando a adesão for ausente. Nas suas recomendações, e quando for apropriado, a Comissão irá sublinhar a necessidade de respeitar o quadro interamericano de regras, especialmente quando um vácuo de normas domésticas contribui para as violações de direitos humanos. A Comissão também irá realizar reuniões técnicas e seminários para os representantes dos Estados membros, organizações da sociedade civil e outros grupos de interesse nos países que ainda não ratificaram os instrumentos interamericanos. Essas reuniões e seminários irão fornecer caminhos para o diálogo e uma troca de visões para identificar quais obstáculos persistem de forma a completar a ratificação. O plano da Comissão é conduzir pelo menos uma atividade deste tipo por ano" (CIDH, 2011, tradução nossa).

18 De acordo com o Plano Estratégico, constituem os três pilares de atividade da CIDH: sistema de petição individual, monitoramento da situação de direitos humanos nos países e áreas temáticas. 
momento crítico, o modo como o objetivo da universalização do SIDH pretende ser institucionalmente trabalhado demonstra que esse obstáculo não consiste em prioridade, pelo menos nesse momento. Ao final desse processo de reflexão, a $\mathrm{CIDH}$ embarcou em um programa de reformas regulamentares e de mudança de práticas para atender a maior parte das recomendações adotadas pelo Conselho Permanente ${ }^{19}$, o que sinaliza a possibilidade de mudanças institucionais graduais acontecerem, ao mesmo tempo em que a $\mathrm{CIDH}$ busca meios para garantir sua continuidade institucional.

Assim, por mais que a CIDH tenha persistido enquanto órgão interamericano e seus poderes tenham sido ampliados ao longo do tempo, é importante refletir para além desses resultados. O foco nas interações entre a CIDH e os Estados não jurisdicionados, durante esses momentos críticos, possibilita questionar o problema da permanência da barreira histórica à universalidade do SIDH - e, portanto, da transformação substantiva do SIDH.

\section{A CIDH e os Estados "em cima do muro"}

Delimitados os momentos críticos do SIDH, passamos à análise da relação entre a CIDH e os Estados não jurisdicionados nesses períodos distintos. No primeiro momento crítico (1969-79), a conjuntura regional parece mais favorável ao desenvolvimento institucional do SIDH, nos moldes hemisféricos. A hegemonia norte-americana se faz claramente presente na OEA e no $\mathrm{SIDH}^{20}$, havendo pouca ou nenhuma oposição à sua política anticomunista ${ }^{21}$. Os países latino-americanos encontram-se praticamente todos sob regimes ditatoriais fortemente alinhados aos Estados Unidos. E, tanto o Canadá quanto os Estados caribenhos ${ }^{22}$, até então, não demonstram interesse em compor a OEA, estando os últimos voltados ao desenvolvimento de regimes regionalmente mais circunscritos. Uma vez

19 As alterações podem ser consultadas na Resolução 01/2013 da CIDH. (CIDH, 2013).

20 Nesse período, o financiamento da OEA dependia, em grande parte, dos EUA, que contribuíam com 2/3 do orçamento da organização. Entretanto, enquanto orçamento e staff da CIDH continuavam a crescer, o orçamento da OEA encontrava-se em tendência inversa. Tal paradoxo se explica em razão dos pesados investimentos dos Estados Unidos no SIDH, que podem ser interpretados como uma vontade política de fortalecer a CIDH, em particular, principalmente entre os anos de 1970-77, e mais acentuadamente no governo Carter (1977-81).

21 Vide o apoio massivo dos Estados à expulsão do governo cubano da OEA, em 1962.

22 O Caribe constitui uma região do continente americano formada por treze Estados soberanos e dezessete territórios dependentes. Desses Estados soberanos, atualmente, apenas três se submetem à jurisdição da Corte IDH: Barbados, República Dominicana e Haiti. Trinidad e Tobago denunciaram à CADH em 1998. 
deflagrados, os processos caribenhos de independência, em geral, mantiveram os novos Estados soberanos alinhados à Comunidade das $\mathrm{Nações}^{23}$, fato que, na conjuntura de um mundo bipolar, contribuiu para que essas novas democracias aderissem ao lado liberal, o que acabou simbolizado pela adesão desses Estados à Carta da OEA e, portanto, ao SIDH. O gráfico abaixo ilustra essa situação em que, à medida que os Estados caribenhos vão se tornando novas democracias, passam a se comprometer, ao menos no plano normativo internacional, com o regime regional de direitos humanos ${ }^{24}$. Para além dos efeitos substantivos da adesão desses Estados no SIDH, o timing de adesão é particularmente relevante para análise das mudanças e continuidades da CIDH durante esse momento crítico.

\section{Gráfico 1. Independências e adesões dos Estados não jurisdicionados ao SIDH}

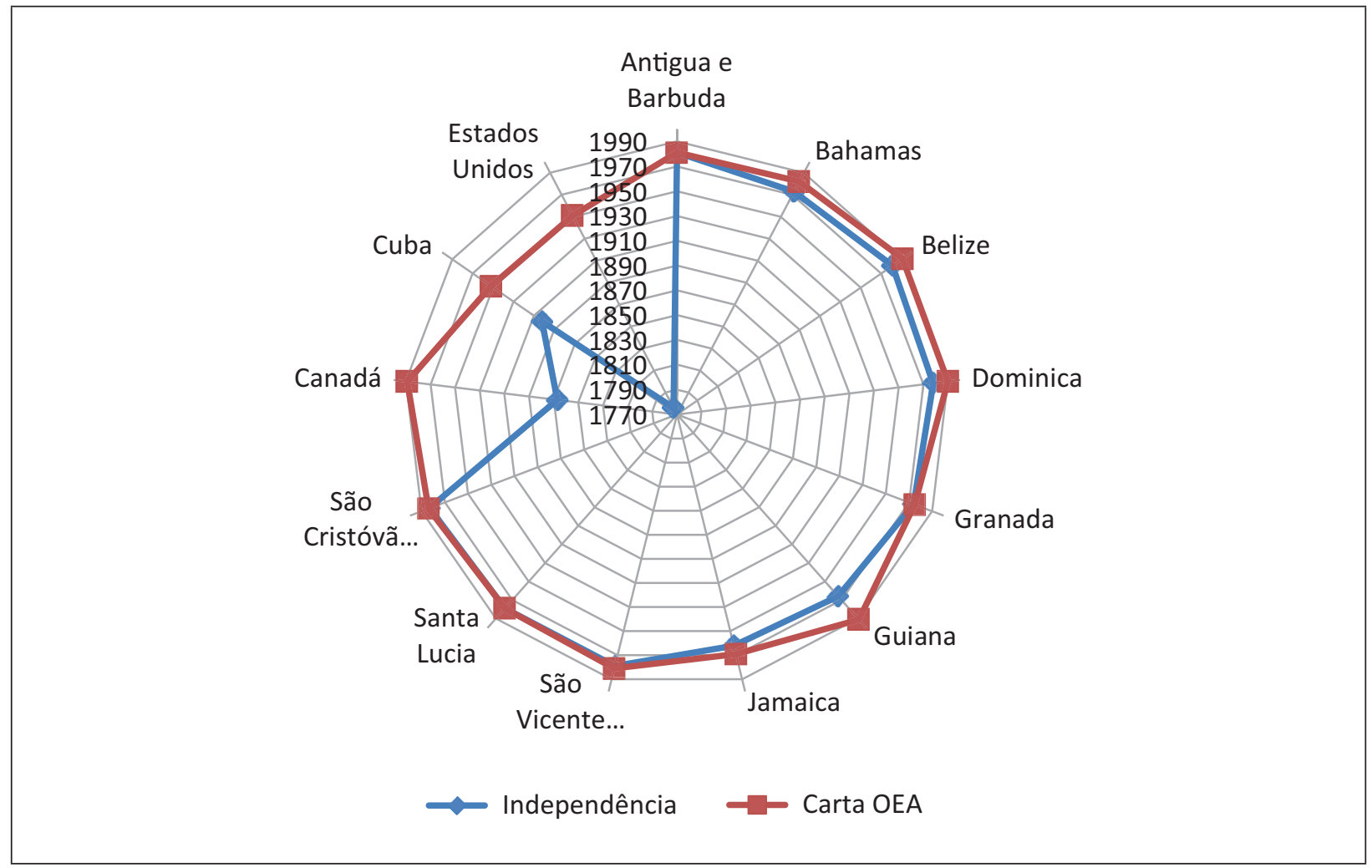

Fonte: Elaboração própria, 2016, baseado em dados de 1770 a 1990.

23 A Comunidade das Nações, anteriormente conhecida como Comunidade Britânica das Nações, é uma organização intergovernamental em que os Estados membros cooperam num quadro de valores e objetivos comuns, definidos pela Declaração de Singapura, que incluem a promoção da democracia, dos direitos humanos, do estado de direito e da paz mundial. A coincidência entre os valores e objetivos da Comunidade das Nações e da OEA contribuiu para a adesão das novas democracias caribenhas ao SIDH. Além disso, o Reino Unido figura como um aliado histórico dos EUA.

24 Nesse sentido, vale um paralelo com o trabalho de Moravcsik (2000), que relaciona o adensamento institucional do Sistema Europeu de Direitos Humanos à democratização e à formação de novos Estados no Leste Europeu. 
A adesão dos Estados caribenhos ao SIDH, mais intensamente durante o primeiro momento crítico, amplia significativamente o número de Estados que passam a compor o regime regional, o que acaba por gerar um elemento de dificuldade quanto à obtenção de consensos sobre normas de direitos humanos mais rígidas e, portanto, de esforços voltados à universalização do SIDH em torno de um padrão único e mais estrito. Assim, a preferência desses Estados pela modalidade não jurisdicionada amplia o rol dos Estados participantes que somente se submetem às normas mais brandas, sedimentando essa posição dentro do SIDH. A conjunção desses dois fatores (ampliação do número de Estados no SIDH e preferência pela posição não jurisdicionada) assume relevância para o entendimento dos rumos do SIDH, porque permite explorar situações em que mudanças institucionais graduais são adotadas como concessões políticas a fim de evitar possíveis rupturas institucionais mais drásticas, como colapso institucional, por exemplo (HELFER, 2002). Esses elementos demonstram que os Estados não jurisdicionados, mesmo se mantendo “em cima do muro", podem figurar um dos elementos explicativos para a continuidade da CIDH durante o primeiro momento crítico, independentemente de outros fatores endógenos geralmente considerados, como, por exemplo, o mérito dos trabalhos e a legitimidade das ações do órgão interamericano. É possível concluir, portanto, que, durante o primeiro momento crítico, a adesão das novas democracias caribenhas à Carta da OEA representa uma contribuição significativa à continuidade da $\mathrm{CIDH}$, particularmente, no momento em que havia perspectivas que tal órgão fosse suplantado pela instituição de um novo órgão interamericano ou de um novo consenso político formalmente mais rígido: a Corte IDH.

Uma participação mais considerável dos Estados não jurisdicionados no SIDH se inicia em meados dos anos de 1990, momento em que a conjuntura internacional e regional torna-se mais favorável, de modo geral, às normas de direitos humanos. A adesão do Canadá ao SIDH em 1989, após longo processo de observação e negociações na OEA, reforça a preferência e a posição política dos não jurisdicionados no SIDH, dando novo fôlego às atividades da $\mathrm{CIDH}$, agora com atribuições compartilhadas com a Corte IDH em pleno funcionamento. Uma das maneiras possíveis de avaliar a relação entre a CIDH e tal grupo de Estados se refere às observações in loco, atividade bastante frequente nesse período. Cerca de $14 \%$ dessa atividade da CIDH se destinou aos Estados não jurisdicionados, de modo que as visitas ocorreram em: Estados Unidos (9 visitas), Bahamas (1 visita), Canadá (1 visita) e Jamaica (2 visitas), embora a grande maioria tenha ocorrido 
na década de 1990. Outro ponto de análise relevante refere-se à abertura política à participação de comissionados de nacionalidades caribenhas na CIDH. De 1970 a 1980, os membros das CIDH advinham principalmente dos grandes países da OEA, como Estados Unidos ${ }^{25}$, Brasil, México e Venezuela, nacionalidades quase sempre representadas no órgão interamericano. Contudo, à medida que mais Estados aderiam ao SIDH, principalmente, a partir dos anos de 1980, a CIDH passou a contar com mais representantes de Estados "menores", estabelecendo-se uma "cota regional não oficial" para assegurar a participação de membros comissionados da América Central e do Caribe (DYKMANN, 2004, p. 79). Considerando que o papel dos indivíduos/comissionados assume um papel fundamental sobre os níveis de compromisso, orientação e iniciativa da CIDH (INTER-AMERICAN HUMAN RIGHTS NETWORK, 2015), o estabelecimento de regras implícitas, que asseguram duas das sete vagas na CIDH para os Estados não jurisdicionados, pode trazer implicações diretas para o manejo das mudanças e continuidades do SIDH.

No segundo momento crítico (2011-2014), a conjuntura hemisférica já se mostra menos promissora ao desenvolvimento institucional do SIDH, conforme exposto na seção anterior. A análise da participação dos Estados não jurisdicionados no SIDH e de suas posições políticas durante o processo de reflexão e reforma da CIDH são elucidativas. Nota-se, nesse segundo momento crítico, um maior envolvimento dos Estados não jurisdicionados no sistema interamericano de petições. Observa-se que, a partir dos anos 2000, esse sistema de petições passa a ser ativado em função de casos individuais relativos aos Estados não jurisdicionados. As decisões (admissibilidade, mérito e medidas cautelares) se avolumam nesse período, observando-se uma maior diversidade de casos e de Estados não jurisdicionados abrangidos. O gráfico abaixo compara a participação dos Estados não jurisdicionados no sistema de petições entre as décadas de 1990, 2000 e 2010. Ainda que essa participação seja limitada, se considerarmos a totalidade dos Estados membros do SIDH, a tendência que se delineia é de crescimento. As projeções ${ }^{26}$ para a década de 2010-2020 revelam que, cada vez mais, os Estados não

25 Os EUA sempre mantiveram comissionados em todas as composições da CIDH: Sandifer (1960-1972), Woodward (1972-1976), Farer (1976-1983), MacColm (1984-1988), Stevenson (1988-1990), Reisman (1990-1995), Goldman (1996-2003), Carozza (2006-2009), Shelton (2010-2013) e Cavallaro (2013-2015).

26 As projeções, nesse ponto, se baseiam meramente no fato de que há, ainda, metade de uma década a ser computada, no período 2010-2019. Trata-se de uma suposição ideal. Projeções mais qualitativas (SALAZAR; CERQUEIRA, 2015) indicam, ao contrário, a diminuição dos números no sistema individual de petições, em especial das medidas cautelares, tendo em vista uma provável atuação de perfil mais baixo por parte da CIDH nos próximos anos. 
jurisdicionados passam a ser abarcados pelo sistema interamericano de petições, em especial, no que se refere às medidas cautelares.

\section{Gráfico 2. Participação dos Estados não jurisdicionados no sistema interamericano de petições}

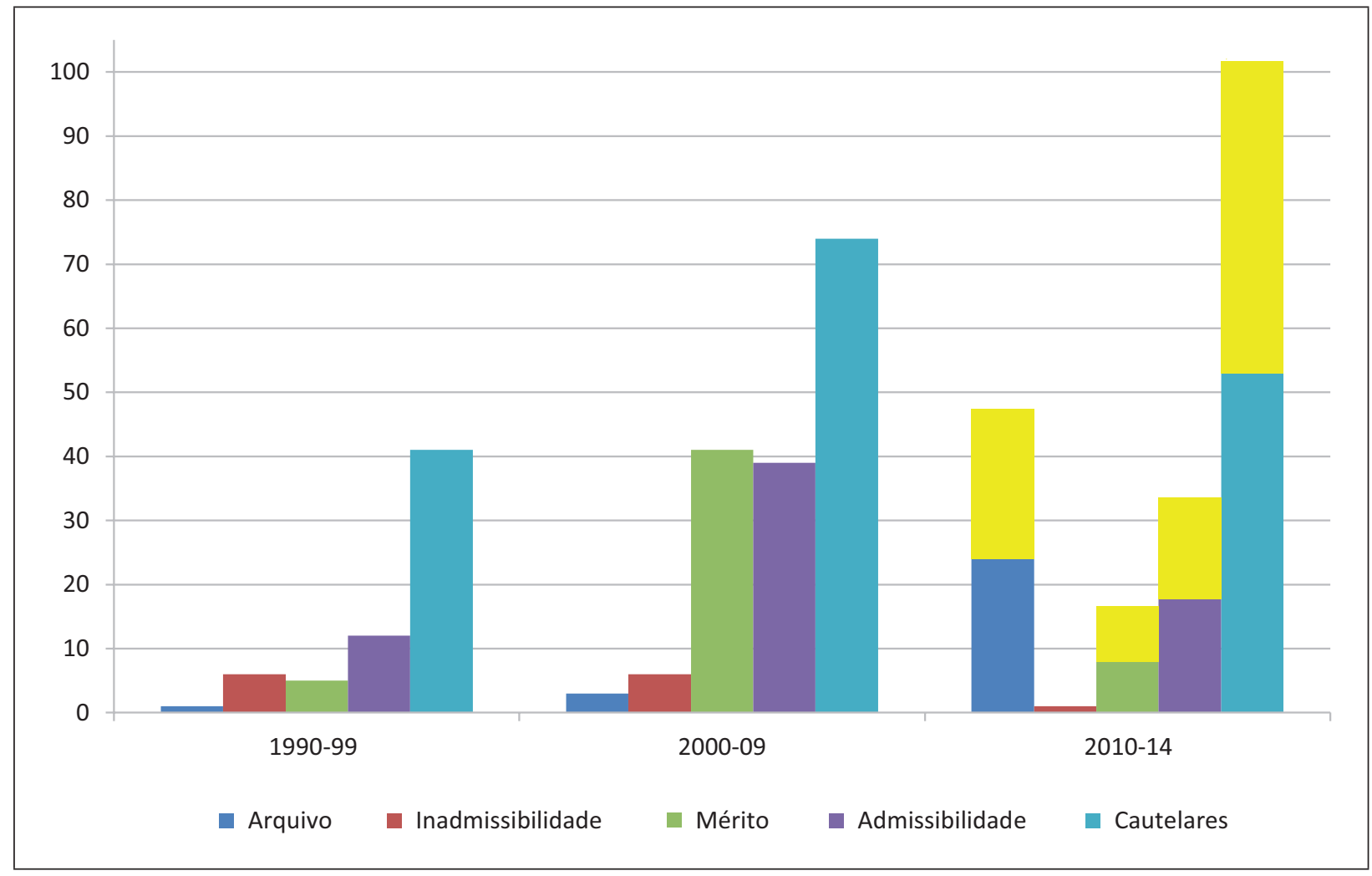

Fonte: elaboração própria com base em dados disponíveis nos Relatórios Anuais da CIDH, 1990 a 2014.

A particularidade sobre as medidas cautelares mostra-se bastante estratégica, pois, dentre as demais medidas adotadas pela $\mathrm{CIDH}$, as cautelares constituem providências mais "brandas": ao mesmo tempo em que sinalizam uma tentativa da CIDH constranger os Estados não jurisdicionados, essas medidas, por natureza jurídica, não consistem em pré-julgamento sobre as violações de direitos humanos. Esse movimento é especialmente importante para legitimar, nesse segundo momento crítico, a necessidade da continuidade do duplo padrão de funcionamento do SIDH, como meio de ressaltar a importância e necessidade da manutenção da ação da CIDH sobre os Estados não jurisdicionados. Tal prática mostra-se útil tanto para a própria defesa institucional da CIDH no processo de reflexão e reforma ${ }^{27}$,

27 No comunicado de imprensa n. 58/21, o Presidente da CIDH afirma: "Uma parte significativa dos trabalhos da Comissão se relacionou a países que não ratificaram a Convenção [...]: de todos os informes de mérito publicados na última década, 44 casos são de países que ratificaram a Convenção, e 25 de países que ainda não o fizeram. Em 2011, por exemplo, três dos cinco informes de mérito publicados são de países que não ratificaram 
como para construção dos discursos de apoio dos Estados não jurisdicionados à continuidade institucional da CIDH. As intervenções feitas pelas delegações dos EUA e Canadá28 nas Assembleias Gerais da OEA, no período de 2010 a 2012, algo incomum nos anos anteriores, são expressões de apoio político e financeiro à manutenção do status quo na $\mathrm{CIDH}$. Representando os Estados caribenhos, as intervenções de Jamaica e Dominica também apoiam a continuidade institucional da CIDH e sinalizam a necessidade de maior inclusão dos Estados caribenhos nas discussões ${ }^{29}$. No que diz respeito à participação de comissionados, nesse segundo momento crítico, são nomeados seis comissionados advindos dos Estados não jurisdicionados (1 de Antígua e Barbuda; 2 da Jamaica, 2 dos Estados Unidos, 1 de Santa Lucia). Outros dois acontecimentos inéditos no SIDH acontecem durante e em sequência a esse período: a CIDH lança um Informe Anual sobre a Jamaica (2012) e recebe doações extraordinárias de Antígua e Barbuda (2016) para manter sua rotina de atividades.

É possível concluir, portanto, que a participação mais qualificada dos Estados não jurisdicionados no segundo momento crítico legitima e fortalece a continuidade institucional da $\mathrm{CIDH}$, ao mesmo tempo que permite a ocorrência de mudanças institucionais graduais ${ }^{30}$, sem que haja, necessariamente, um direcionamento à superação do obstáculo para a universalidade do SIDH. Tanto a forma como os Estados não jurisdicionados participam do SIDH, como o modo com que a CIDH lida com esses Estados parecem demonstrar que os interesses de ambos os atores convergem para que o foco do SIDH se volte mais a outros objetivos (como, por exemplo, o adensamento institucional do SIDH no âmbito de sua atuação sobre os Estados jurisdicionados) do que à universalização. As frequentes menções da CIDH à importância do SIDH para os Estados não jurisdicionados e

a Convenção: um sobre o Canadá que se relaciona ao devido processo em matéria de imigração e dois sobre os Estados Unidos, um relacionado ao devido processo e à pena de morte, e o outro aos deveres do Estado para prevenir e responder à violência doméstica. Com relação às medidas cautelares [...] no ano de 2011 os dois países com mais medidas cautelares outorgadas pela Comissão foram Honduras, com 12, e Estados Unidos, com 11 [...] a Comissão Interamericana foi a primeira organização intergovernamental que solicitou medidas especiais de proteção a favor dos presos pelos Estados Unidos em Guantánamo, e a Comissão Interamericana solicitou reiteradamente o fechamento imediato de tal centro de detenção" [tradução nossa]. Comunicado de Imprensa n. 58/12, 06. jun. 2012. Disponível em: < http://www.oas.org/es/cidh/prensa/comunicados/2012/058.asp > . Acesso em: 16 set. 2015.

28 OEA. Intervenções disponíveis em: < http://www.oas.org/es/cidh/informes/anuales.asp > . Acesso em: 16 set. 2015.

29 Idem.

30 Um exemplo de mudança institucional gradual foi o aperfeiçoamento dos pré-requisitos para lançamento das medidas cautelares, ao fim do processo de reforma 2011-2013. 
o avanço participativo desses Estados no SIDH representam uma comunhão de interesses entre atores de natureza diversa para manter o status quo do SIDH. Nesse ponto, é importante destacar a reconfiguração dos papeis agente-estrutura nos momentos críticos. Em ambos momentos, a CIDH age, por meio de seus poderes (revisão de normas estruturais - estatuto e regulamento; emissão de notas oficiais; participação nos processos de reforma etc.) para alcançar seus objetivos (sobrevivência institucional, no limite). Esse alinhamento de interesses entre CIDH e Estados não jurisdicionados quanto à continuidade institucional da CIDH mostra-se importante para contrabalancear tanto as investidas críticas de alguns Estados (Brasil, Bolívia, Venezuela, Equador) em promover mudanças institucionais substantivas na CIDH, quanto, indiretamente, para mitigar a influência das novas organizações multilaterais na região, tendentes a lidar com questões de direitos humanos (IPPDH-Mercosul, Grupo de Alto Nível de Cooperação e Coordenação em Direitos Humanos-UNASUL, Conferência de Estados partes da CADH).

Por fim, duas leituras mostram-se possíveis a respeito da participação dos Estados não jurisdicionados ao longo da trajetória institucional do SIDH: de um lado, representam, de fato, um impasse à universalização do sistema regional; de outro, podem ser entendidos como um elemento de estabilidade dentro de um sistema regional que funciona por meio de um padrão duplo, e que, por essa razão, é alvo de constantes questionamentos. No caso desse último entendimento, ao contribuírem para a continuidade da $\mathrm{CIDH}$, os Estados não jurisdicionados sustentam a manutenção do SIDH no âmbito hemisférico.

\section{Conclusões}

O enquadramento do SIDH enquanto um espaço de disputas políticas, assim como a escolha dos Estados “em cima do muro" como foco desta pesquisa possibilitam alguns ganhos analíticos relevantes ao exame da mudança e continuidade institucional do regime regional de direitos humanos. O primeiro deles refere-se à desmistificação da ideia de que os Estados "em cima do muro" assumam posições politicamente indefinidas, papéis inerciais e presença obstrutiva no SIDH, simplesmente. O segundo diz respeito à capacidade de explicação do SIDH não somente a partir de um ponto de vista exógeno (choques estruturais, como Guerra Fria, crises financeiras, movimentos de integração regional), tampouco puramente endógeno (relevância do trabalho institucional, legitimidade da ação 
institucional). O reconhecimento da reconfiguração dos papéis agente-estrutura e das coalizões políticas (mais ou menos explícitas) nos momentos críticos do SIDH permitem visualizar como a mudança e a continuidade institucional são resultados de processos de contestação e (re)interpretação das regras institucionais. Destaca-se, nesse estudo, como as variáveis institucionais (financiamento do SIDH, origem dos comissionados, representatividade regional no órgão) - ainda pouco exploradas - assumem importância, quando associadas aos elementos de poder.

No que se refere às conclusões substantivas referentes ao exame da trajetória institucional do SIDH, os resultados da pesquisa questionam a ideia de que esse grupo representa apenas impasse à universalização - e, portanto, à transformação - do SIDH. Ao contrário, as análises sugerem que, apesar de comprometidos em menor grau, a presença e a participação dos Estados não jurisdicionados no SIDH podem representar um elemento de estabilidade do sistema regional, que permitiu não apenas forjar o design institucional e funcionamento peculiar do SIDH, mas também a própria continuidade do sistema regional de direitos humanos, ao representarem a construção de um fator de estabilidade institucional dentro de um panorama regional persistente de questionamentos da própria ideia de proteção interamericana dos direitos humanos na região.

\section{Referências}

ALVES, J. A. L. A arquitetura internacional dos direitos humanos. São Paulo: FTD, 1997. AMORIM, C. O Brasil e os direitos humanos: em busca de uma agenda positiva. Política Externa, v. 18, n. 2, 2009, p. 67-75.

BASCH, Fernando; et al. A eficácia do sistema interamericano de proteção de direitos humanos: uma abordagem quantitativa sobre seu funcionamento e sobre o cumprimento de suas decisões. Sur, v. 7, n. 12, 2010, p. 09-35.

BUERGENTHAL, Thomas. Remembering the early years of the Inter-American Court of Human Rights. In: Center for Human Rights and Justice Working Paper n. 1, 2005, New York, p. 01-17. Disponível em: < http://www.corteidh.or.cr/tablas/31422.pdf > . Acesso em: 06 Fev. 2017.

CAVALLARO, J.; BREWER, S. O papel da litigância para a justiça social no Sistema Interamericano de Direitos Humanos. Sur, v.5, n. 8, 2008a, p. 84-99.

CAVALLARO, James L.: BREWER, Stephanie E. Reevaluating regional human rights litigation in the twenty first century: the case of the Inter-American Court. American Journal of International Law, v. 102, 2008b, p.768-827. 
COMISSÃO INTERAMERICANA DE DIREITOS HUMANOS. Comunicado de Imprensa n. 58/12, 06. Jun. 2012. Disponível em:<http://www.oas.org/es/cidh/prensa/ comunicados/2012/058.asp > . Acesso em: 16 Set. 2015.

COMISSÃO INTERAMERICANA DE DIREITOS HUMANOS. Plano Estratégico: 2011-2015. 2011. Disponível em: < http://www.oas.org/en/iachr/docs/pdf/IACHRStrategic Plan20112015.pdf > . Acesso em: 14 set. 2015.

COMISSÃO INTERAMERICANA DE DIREITOS HUMANOS. Resolução 01/2013. 2013. Disponível em: < http://www.oas.org/es/cidh/decisiones/pdf/Resolucion1-2013esp. pdf $>$. Acesso em: 15 Fev. 2015.

DYKMANN, K. Human rights policy of the Organization of American States in Latin America: philanthropic endeavors or the explotation of an ideal? Princeton: Markus Wiener Publishers, 2004.

DONNELLY, Jack. International human rights: a regime analysis. International Organization, n. 40, v. 3, 1986, p. 599-642.

DONNELLY, Jack. Universal human rights in theory and practice. New York: Cornell University Press, 2003.

ENGSTROM, Par. A special relationship gone normal? Argentina and the Inter-American Human Rights System, 1979-2013. Pensamiento Proprio, v. 38, n. 18, 2013, p. 115-147. FARER, T. J. The grand strategy of the United States in Latin America. New Brunswik, 1988. FARER, T. J. The rise of the Inter-American human rights regime: no longer a unicorn, not yet an ox. Human Rights Quarterly, v. 19, n. 3, 1997, p. 510-546.

FORSYTHE, D. Human rights, the United States and the Organization of the American States. Human Rights Quarterly, v. 13, n.1, 1991, p. 66-98.

FRANÇA, T. C. N. De observador a membro integral: a lenta caminhada multilateral do Canadá em direção à OEA (1972-1990). Interfaces Brasil-Canadá, v. 13, n. 16, 2013, p. 113-130.

GOLDMAN, Robert K. History and action: The Inter-American Human Rights System and the role of the Inter-American Commission on Human Rights. Human Rights Quarterly, v.31, n. 4, 2009, p. 856-887.

GOLDSTEIN, J. et al. Introduction: Legalization and World Politics. International Organization, v. 54, n. 385, 2000, p. 393-96.

HELFER, L. Overlegalizing human rights: International Relations Theory and the Commonwealth Caribbean backlash against human rights regime. Loyola - Los Angeles Law School. Legal Studies Research Paper Series, Paper n. 13, 2002, p. 1832-1911.

INTER-AMERICAN HUMAN RIGHTS NETWORK. The Inter-American Human Rights System: The Law and Politics of Institutional Change. Workshop Summary. Institute of the Americas, University College London: 9-10, October 2015. Disponível em: $<$ http://interamericanhumanrights.org/wp-content/uploads/2015/11/IAHRNLondon-Workshop-Summary-v02.11.151.pdf > . Acesso em: 18 set. 2016. 
JIMÉNEZ, M. et al. Hacia un modelo de transparencia y acceso a la información en el sistema interamericano de derechos humanos. In: MAIA, C. B. et al. Desafíos del sistema interamericano de derechos humanos: nuevos tiempos, viejos retos. Bogotá: Centro de Estudios de Derecho, Justicia y Sociedad, Dejusticia, 2015, p. 108-42.

LUTZ, Ellen L.; SIKKINK, Kathryn. International Human Rights Law and Practice in Latin America. International Organization, v. 54, n. 3, 2000, p. 633-659.

MAHONEY, J.; THELEN, K. Explaining institutional change: ambiguity, agency and power. New York: Cambridge University Press, 2010.

MEDINA, Cecilia. The Inter-American Commission on Human Rights and the Inter-American Court of Human Rights: reflections on a joint venture. Human Rights Quarterly, v. 12, 1990, p. 439-464.

MORAVCSIK, A. The origins of human rights regimes: democratic delegation in postwar Europe. International Organization, v. 54, n. 2, 2000, p. 217-252.

MUÑOZ, A. A.; ZICCARDI, N. S. El processo de reforma al sistema interamericano de derechos humanos (2011-2013): crónica reciente y desafíos futuros. Pensamiento Proprio, v. 38, n. 18, 2013, p. 13-18.

ORGANIZAÇÃO DOS ESTADOS AMERICANOS. Protocolo de Buenos Aires. Disponível em: < http://www.oas.org/dil/esp/tratados_B-31_Protocolo_de_Buenos_Aires.htm > . Acesso em: 06 Fev. 2017.

ORGANIZAÇÃO DOS ESTADOS AMERICANOS. Convenção Americana de Direitos Humanos. 1969. Disponível em: < http://www.cidh.oas.org/basicos/portugues/c. convencao_americana.htm > . Acesso em: 06 Fev. 2017.

ORGANIZAÇÃO DOS ESTADOS AMERICANOS. Declaração Americana de Direitos e Deveres do Homem. 1948. Disponível em: < https://www.cidh.oas.org/Basicos/ Portugues/b.Declaracao_Americana.htm > . Acesso em: 06 Fev. 2017.

ORGANIZAÇÃO DOS ESTADOS AMERICANOS. Protocolo de San Salvador. 1988. Disponível em: < http://www.cidh.oas.org/basicos/portugues/e.Protocolo_de_San_Salvador. htm > . Acesso em: 06 Fev. 2017.

PASQUALUCCI, Jo M. The practice and procedure of Inter-American Court of Human Rights. Cambridge, New York: Cambridge University Press, 2003.

PIOVESAN, F. Proteção dos direitos sociais: desafios do ius commune sul-americano. Revista do TST, v. 77, n.4, 2011, p. 102-39.

RAMOS, André de Carvalho. Direitos humanos em juizo: comentários aos casos contenciosos e consultivos da Corte Interamericana de Direitos Humanos. São Paulo: Max Limonad, 2001.

REZENDE, F. da Cunha. As instituições mudam endogenamente?: limites e possibilidades da mudança institucional endógena na Teoria Institucional Contemporânea. Revista Brasileira de Informação Bibliográfica, n. 76, 2013, p. 33-61. 
SALAZAR, K.; CERQUEIRA, D. Las atribuiciones de la Comissión Interamericana de Derechos Humanos antes, durante y después del processo de fortalecimiento: por un balance entre lo deseable y lo posible. In: MAIA, C. B. et al. Desafíos del sistema interamericano de derechos humanos: nuevos tiempos, viejos retos. Bogotá: Centro de Estudios de Derecho, Justicia y Sociedad, Dejusticia, 2015, p. 144-189.

SHOULTZ, L. Human rights and United States policy toward Latin America. Princeton, 1981. SIKKINK, K.; WALLING, C. O impacto dos processos judiciais de direitos humanos na América Latina. In: REIS, Rossana R. (Org). Políticas de Direitos Humanos. São Paulo: Hucitec, 2010, p. 94-124.

STEVENSON, B. J. R. O ingresso no Sistema Interamericano: o Canadá e a OEA. Contexto Internacional, v. 16, n. 1, 1994, p. 117-144.

THEDE, Nancy; BRISSON, Hughes. International relations and the Inter-american system of human rights promotion and protection: strategic exploitation of windows of opportunity. Quebec Journal of International Law. Edição especial, 2011, p. 07-36.

TRINDADE, A. A. Cançado. A consolidação da capacidade processual dos indivíduos na evolução da proteção internacional dos direitos humanos: quadro atual e perspectivas na passagem do século. In: PINHEIRO, Paulo S.; GUIMARÃES, Samuel P. (orgs.). Direitos humanos no século XXI. Brasília: IPRI, 2002, p. 19-48. 